Arte, Individuo y Sociedad

ISSN: 1131-5598

http://dx.doi.org/10.5209/ARIS.54887

\title{
Francesca Rosenberg on her experience as Director of Community, Access, and School Programs at the Museum of Modern Art (New York).
}

2 May, 2016

Floor 2 Museum of Modern Art (New York)

Francesca Rosenberg is the Director of Community, Access, and School Programs. She has played a key role in the inception of programs working with people living with dementia and their care partners at MoMA. Part of her activity includes the launch of the Meet Me program and The MoMA Alzheimer's Project: Making Art Accessible to People with Dementia.

\section{Introduction. The state of the art in alzheimer's programs}

Q: Thanks to all the documentation produced around the positive effects for people living with dementia and their care partners, there is no longer a shadow of doubt that launching a program for this audience, is something likely to lead to a benefit for this community. If this is so clear, why aren't there more programs for people living with Alzheimer's disease?

F: I would say there are! I mean, I don't know what you consider a lot but... what we have been able to document is that now 125 institutions from different places all over the world have committed to working with people with dementia and their care partners with support provided by MoMA.

When we launched our initiative back in 2006 there were very few. We really have been able to connect with a lot of places and I think it is like a snowball, starts small and then it gets bigger and bigger and bigger as it is rolling.

When we held one of our conferences a few years ago, we put up a big map and put little pins where there were programs. It was interesting because some people there thought "oh! well there are no programs in my place so I want to do something about that". Since then, there have been more additions to the map. We've reached over 400 museums through conference presentations and workshops. 245 of those institutions are international, representing 25 countries. These numbers account for in-person presentations only; they do not account for visits to the Meet Me website.

There can always be more and we will continue to help any groups or individuals interested in taking this on. And I think what's interesting is that it is not just one type of museum. Any type of museum can be doing this. From small to big, to modern art to historical, to a science center, a botanical garden... the most important thing I think is really just having the staff that is dedicated to creating it and sustaining it. 


\section{Origins of MOMA working with people with alzheimer's disease}

\section{Q: How did the program start at MoMA?}

F: MoMA has a really long history of serving people with disabilities, dating back to the 1940s when MoMA launched the War Veterans' Art Center. They were trying to help veterans readjust to civilian life and using art to help them in that process. I think that all the programs we offer through MoMA's Community and Access Programs, are meant to serve different audiences and I feel that this was a natural fit for us because we have educators that are very well trained for working with adults, who have a great sensitivity, and great interest in bringing out the best in people. They can also work very well in terms of not only focusing on the person with Alzheimer's disease but also their care partner. The team needed to learn certain things that are specific to this audience, and we received this information from some outside organizations that really specialize in it from a more medical point of view. We were able to also learn communication strategies and trouble-shooting and combine that information with the expertise required in Museum Education. I feel like the two came together beautifully. And it just made sense with the numbers! The staggering numbers of people that are being diagnosed with this disease and the aging population! I never thought of it as being so different from what we had already been doing for many, many years for other audiences with disabilities. You know when I started at MoMA there were a few programs for people who were deaf, there was a touch tour for people who were blind but that was really it. And so, I just started thinking, looking at the population and looking at the needs and it just kind of fit in to that.

Q: Were you present when the first session took place?

F: Yeah! The first one we actually piloted in Queens in our temporary space there. It was a group of individuals who came from an assisted living facility. That kind of experience is a little bit different, because everybody knows each other. And they are coming with aids from the facility. Logistically it was much easier because they traveled together by bus and we just had one point of contact with the coordinator. When we moved back to MoMA and really launched Meet Me in 2006, we had the challenge of getting people to midtown Manhattan, and touring them though much more crowded galleries, with crowds and the challenge of acoustics. It is also a much heavier administrative workload to register individual families for the program. We can now have up to 100 people attended each month.

\section{Q: Did you need special funding to launch the program?}

F: We didn't need special funding to begin it because it was under the umbrella of MoMA's Access Programs. We were able to pilot these programs using our existing budget. When we saw how successful this was, we made a commitment to offer it on a regular basis. (...)

We continued to work with the assisted living facilities but we also wanted to serve those individuals that are still living at home that may just have a husband or a wife or may have a professional aid. For the program, individual family units are assigned to a small group that is led by a trained museum educator. It was the 
generosity of the Metlife Foundation that enabled us to take what we were learning here to share it at workshops and conferences first nationally and then internationally (The MoMA Alzheimer's Project). Their grants enabled us to write a book that has since been translated into Spanish, Japanese, and Swedish and to develop an extensive website (http://www.moma.org/meetme). But I don't think that museums really need that. It is wonderful and we couldn't be more grateful for having it but I do believe that museums again, big or small can take this on as long as they have staff that is dedicated to doing and sustaining it.

Q: What would you recommend for a team that is starting up an Alzheimer's program?

F: I would say that they should link up with an outside organization that specializes in the disease and have them do a training for the educators that includes all the information about the disease and how it impacts the brain, and what parts of the brain are still functioning quite well. That kind of training is really important very early on and then hopefully that outside organization can also help pull together an audience. Then I would say not to throw a wide net but just really to work with one group, maybe two groups and to pilot the program, experiment with a couple of different works of art and a couple of different sequences of those works, maybe different themes, and explain to that group "you are the pilot group and we hope you give us the feedback of what worked well and what we need to do differently next time." And then I think you see and you learn from that and this doesn't cost a lot of money. It's the educators' time, art supplies if you are offering any art making, the costs for paying for security if necessary and refreshments if you are planning on offering them. Refreshments are always appreciated (laughs) and the importance of having time for social connection cannot be underestimated. Studies show that social isolation can be the equivalent of smoking 15 cigarettes a day.

\section{Current practice: evolution and changes}

Q: In the videos I've seen, the galleries seem very quiet. Was it because the museum was closed to the general public those days?

F: MoMA used to be closed on Tuesdays. The whole day was without the general public and we used to do many of our access programs on that day. But then, a few years ago, we opened on Tuesdays. Now we are open seven days a week. We have tried to keep that same atmosphere and I think we have succeeded in some ways. The museum has been of great support to figure out how we can do this best. For instance, our Access groups have a chance to visit is some special exhibitions even before they open to the public. What's nice is that they are really like the VIPs, they come in before anybody else. And they have the galleries all to themselves. That has really helped us. The challenge still is getting from the lobby which can be very crowded and upstairs to the exhibitions. But once we get in there, and we take a deep breath, and the educator sort of focuses everybody and the attendees start to look, and think, and experience the work, it really changes the mood. When people first come in, they can seem very agitated. They might visibly look uncomfortable, but our trained educators and volunteers go up to each person, to welcome them, to tell 
them how happy they are that they are here, that we are happy that they made it. This helps to reset their feeling and their mood. It really seems to change the tone.

Q: How do you organize a visit and what are the criteria for choosing the works of art that will be part of the visit?

F: It varies, but the program starts at $2.30 \mathrm{pm}$ and it goes until $4.00 \mathrm{pm}$. In that time, we might look at five works. We could also look at six or four. I would say somewhere between four and six. Individual stools are always provided so the attendees can feel comfortable. We spend time in front of works of art that are quite varied. Paintings, sculpture, photographs, prints are all good because they don't require memory. All the information is right there in front of the viewer. Video works can be problematic because they do require remembering what you've seen. We include works that are both representational as well as abstract. We have a very extensive collection as well as special exhibitions that are of interest to most people. Our challenge is to use works that are in less crowded spaces (if we are touring an exhibition that is open to the general public). We've found some of the most interesting conversations have been in front of things that are somewhat representational but ambiguous. You know where there is a bit of a mystery, it's not very concrete what's happening, and that holds true for any audience. Like "Christina's World" by Andrew Wyeth. Why is that? Why are people drawn to this image? It is because you can't see the face. You can't read the woman's expression so it leaves people guessing.

\section{Q: Do you have art-making sessions?}

F: Yes. It is interesting. What we tried out first was we added in some art making to the Meet Me at MoMA program. Some simple kinds of activities like sketching in the galleries. And some people loved it and other people did not love it. And I think that the people that didn't love it thought, "this is not what this program is. I'm used to coming in and just looking and talking. And now you are asking me to do this, and I haven't drawn since I was five." And you know for some people there is a hypersensitivity to infantilizing. They felt like "you are treating me like a child, and I don't like it." Others, on the other hand, really enjoyed this new element. What we ended up doing instead, was to offer specific art making programs that were advertised as having this component. And then we had a self-selecting audience of people truly interested in making art and it worked out much better. Some of these individuals have been making art all their lives. But there are other people too that had never done this before. There are great stories of people that really had never been creative in this way and then they fell in love with it. They found a whole new focus. They started painting at home and getting a studio, exhibiting their work, selling their work. I think it is very individual. And I think just as long as you give people the option... people want choice! they don't want to be told "you are doing this"! I do think it can be very successful.

Q: How has the program evolved?

F: We started in Queens, a very quiet place with groups coming to us as groups. And then here in Manhattan, at a much bigger place, the logistical challenges and meeting 
the people down and leading them through the galleries and the work of reaching out to individual families. It is much more administratively heavy undertaking at this point. Individual families you have to check them in and give them headsets for sound amplification. It is not necessary for everyone but we actually encourage everyone to wear them because that way if it is very crowded in the gallery it is easier to hear. We provide the stools. We learnt as I said earlier how to incorporate art making. We have experimented with different things over the years. We have done a bit of work with thinking about dividing people who are in a later stage of the disease. I think there are pros and cons to doing that. But there were some people that... some care partners who said you know "I think this is too fast pace for my loved one". And then we thought "ok, how can we slow it down?" while still keeping these people that are still able to, you know, to move quickly through the ideas and the works. It is always a balancing act. We were able to do this because we know our audience pretty well, at least the returning visitors. If there are a hundred people that show up for our monthly program, let's say we know 70 of them. For example, we would know that John has verbal skills but they are limited. But if you give him the time he will verbally communicate. So, we would put John with Sarah. Sarah has no verbal skills but she makes eye contact, she can shake her head and she would be great in that group. So, let's put them together and we started like handpicking people. And then we really sat down with the educators and said "ok, this is gonna be a very different feeling group from what you are used to doing. What we want you to do is start with a bigger question and see who responds. For example "what do you think about Klimt's women? the woman in this painting, What do you think she is doing?" And then see if anybody responds. If nobody responds, then we might say "what colors do you see in this?" And then maybe one person might be able to say "blue or red". Then you might turn it into a yes or no question. You know, "do you like this work? Is it something you would run to see every day?" And kind of from that see... The educator that usually stands in the front of the group at this late stage might go to each person very slowly. She would take her arm, maybe touch her on the shoulder. And really direct the question to them and wait. Maybe bend down, be at the level of the person using a wheelchair. And we found that that really made a difference for some of the participants. They really look awakened and engaged. A sort of a change had come over them in this time because the educator had taken the time to connect with them. I feel like it can be a little bit uncomfortable for the educator when they are new to this kind of group because they are used to being in front taking questions and answers from everybody. To have this kind of quiet can be a little unsettling. But if you can be comfortable with that and be patient, you can have some very special moments that I think can go a very long way. If you can have somebody in that group that also is a bit more verbal, than everybody gets to hear from that person as well and there is a benefit to that. But again, that person needs to be the kind of person that is ok with the quiet that comes after. It is this sort of fine line. It doesn't always work but it is worth trying.

Q: What's the role of the care partner?

F: The role of the care partner is usually very participatory. What I notice in these programs is that very often you cannot tell who is the care partner and who is the person with Alzheimer's. That is I think the beauty of the program. Because nobody 
is identified one way or the other. It is never discussed. Everyone is asked to speak and share his/her thoughts and ideas. And we all know that this is just as hard for the care partner in many ways as it is for the person that has been diagnosed. There is such a high level of depression and isolation and burden and hardship for the care partner that we wanted to make a program where they felt included and valued. To get their creative thinking going and give them a respite from thinking about the disease and what's going on. To give them time to just be in a beautiful environment with incredible works of art and to feel connected to the person they came with. To feel connected to the educator, to feel connected to the other people in the group that are going through similar things. Feeling connected to an institution like this. Those are all goals that we have for the program. What ends up happening from time to time is that after the person that has been diagnosed dies, the care partner wants to stay connected to the MoMA. In some cases they have actually become volunteers working specifically on this program but also working in other aspects of the Museum. But that was also how we ended up developing Prime Time. In this new initiative for people 65 and older we can continue to have a relationship with these people but in a different way now that they are in a new stage of their life. We offer programs, tours, studio classes, films, and more just for them.

\section{Future}

Q: What's the future of the activity related to Alzheimer's audience?

F: Meet Me at MoMA will hopefully always be on offer here at MoMA. We will continue to offer a monthly program, for people who have been diagnosed with dementia and their care partners. There is also the welcoming of groups that come from assisted living facilities and outside care organizations. We have our educators who lead these programs who continue to train. Most of them are veterans that have been here for a long time and they feel very comfortable working with these audiences but if we get new people on board, part of their training is thinking and learning about how they will work with this particular population. That's ongoing. What we were able to do through the MoMA Alzheimers' project funded by the Metlife Foundation was broader outreach across the country and internationally. I feel like what we were able to do had such a great impact that continues to grow. Now, to have 125 museums that are working to offer their own programs in their own way to their own local audiences is the greatest gift that we could give. Going forward we will continue to have the Meet Me website as an ongoing resource that people can refer to. We still get calls from all over the world, from our colleagues at different institutions that might be at different stages of the process but want a little bit of our input. And we are more than happy to share it. We are also always learning and value hearing from colleagues about strategies that have worked and that haven't worked. We are always eager to do what we can to keep things fresh. 


\section{Impact}

Q: Would you say that the Meet Me program has had an impact at an institutional level?

F: Absolutely. It has a ripple effect. It is not just a program. It has become part of the DNA of the institution. It has an impact on how the public perceives the institution as well. So, it is happening internally and externally. And in both cases, it is happening in very positive ways. Internally what ends up happening also is that it benefits everybody: all the visitors. Because first of all they see what we are doing and they think "oh, this is a place that cares about people." But it also helps staff to think about the diverse audiences that visit the museum and what their needs might be. Certainly, our educators have told me that they have learnt so much from working with this particular population that can then be transferred to working with other groups of individuals. 
